\title{
From kiosks to megastores: The evolving carbon market
}

\author{
by Deb Niemeier and Dana Rowan
}

Markets can play a key role in mitigating the effects of climate change by providing added flexibility, allowing emissions reductions to occur at a lower cost while maintaining a set level of emissions reductions. With careful regulatory design, both industry and consumers can benefit from low costs. We review the state of carbon trading globally and in the United States, the West and California. New policies and regulations related to $A B 32$, which mandates reductions in California's greenhouse-gas emissions to 1990 levels by 2020, are beginning to take shape. California has a unique opportunity to establish a new ethos for carbon trading by acknowledging unavoidable mitigation costs, and by designing a market-based solution that is fair, equitable and transparent, and protects the most vulnerable members of society.

$\mathrm{T}$ The carbon market is growing exponentially; at $\$ 30$ billion, worldwide trading in 2006 was nearly triple that observed in 2005. A carbon market is created when an emissions cap is set either through a political or regulatory process - and an emissions allowance is then passed down to regulated entities. If the total carbon emissions produced by a company exceeds its cap (or allowance), then the company must purchase credits (or allowances) from those polluting less than their allowance; this transfer is known as a carbon trade. In theory, carbon markets allow companies to choose least-cost methods of compliance, which results in a net societal financial gain when overall emissions are reduced to the desired level. Today's carbon market can be loosely organized into the regulated (or compliance) market and the voluntary (or noncompliance) market; the volume and value of

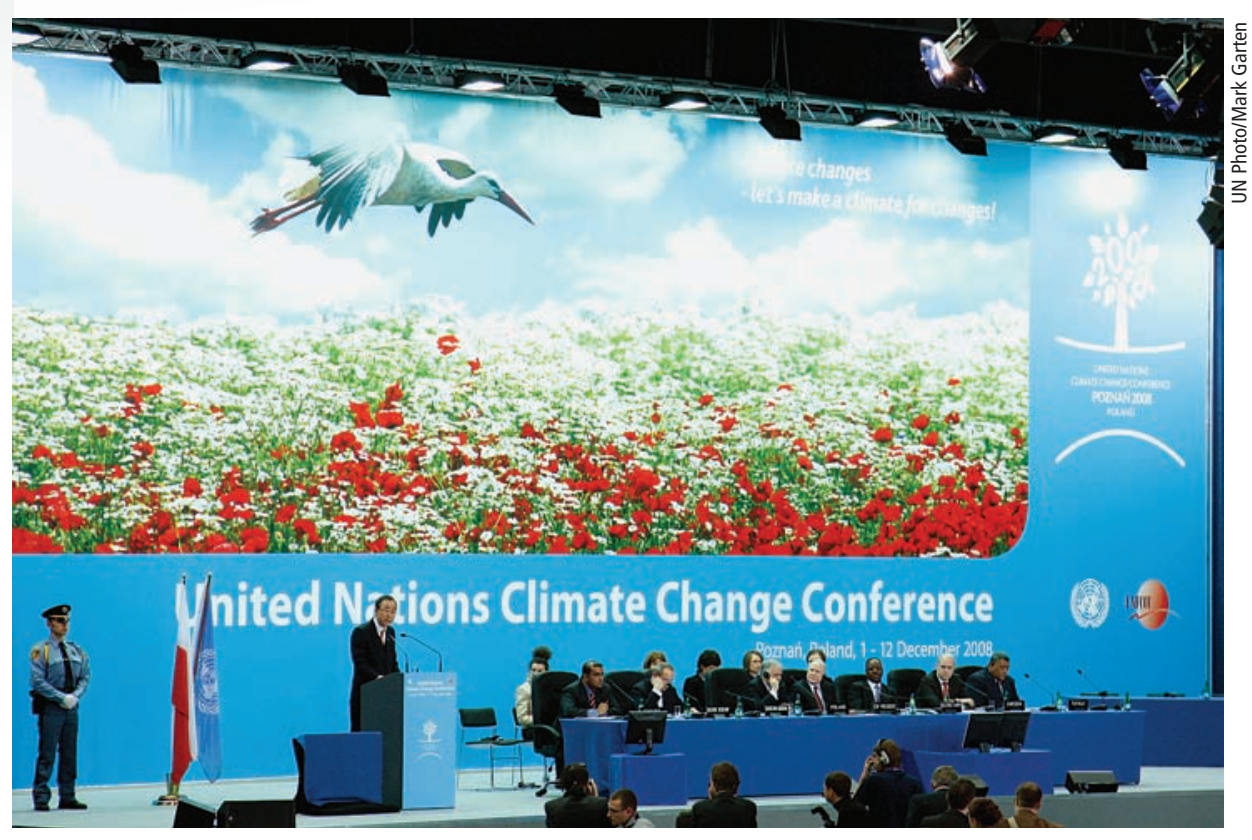

Globally, carbon trading is expanding rapidly as a means for using markets to reduce greenhouse-gas emissions. In December 2008, Secretary-General Ban Ki-moon opened the United Nations Climate Change Conference in Poznan, Poland.

trading is substantially greater in the former than in the latter (fig. 1). Both types of markets trade in greenhousegas emissions, which include carbon dioxide, methane, nitrous oxide, sulphur hexafluoride, hydrofluorocarbons and perfluorocarbons, and are measured in carbon dioxide equivalents $\left(\mathrm{CO}_{2} \mathrm{e}\right)$.

When regulated entities are subject to greenhouse-gas limits, those emitting less than the cap can theoretically trade with those emitting above the cap. Carbon trades can also occur with offset projects that reduce emissions from unregulated greenhouse-gas-producing activities (such as capturing methane from cows in California and using it to produce electricity), or via unregulated carbon-sequestration activities (such as planting trees in Brazil).

The regulated carbon market transacts about a million metric tons of carbon dioxide equivalents $\left(\mathrm{MMtCO}_{2} \mathrm{e}\right.$, the standard measurement for amounts of greenhouse gases emitted into the environment) annually, and includes the European Union Emissions Trading Scheme, the United Kingdom Emissions Trading Scheme, the New South Wales Greenhouse Gas Abatement Scheme, and offset projects certified under the Kyoto Protocol, a 1997 international treaty to reduce greenhouse gases.

The voluntary carbon market includes the Chicago Climate Exchange, which allows businesses to voluntarily set a reduction target and trade emissions or buy offsets. Individuals and businesses can also purchase retail "over-the counter" greenhouse-gasemissions offsets, such as TerraPass. The voluntary market, which has been referred to as "the Wild West" of offset trading (Fahrenthold and Mufson 2007), currently transacts about $24 \mathrm{MMtCO}_{2} \mathrm{e}$, and this amount is projected to roughly double by 2011.

\section{Carbon market history}

Voluntary emissions reductions and offsets can be traced back at least 20 years, driven by the desire to reduce greenhouse-gas emissions in the absence of formal regulations. Nonetheless, the decision to allow offsets is separate from the decision to impose a regulatory cap. In addition, the types of projects allowed as offsets and the criteria by which they are evaluated are also policy decisions. When credits are generated through offset invest- 
ments, the transaction costs - the costs of providing the services, information and enforcement required to support a trade - may be much higher than anticipated and are directly related to policy decisions about how to evaluate and monitor projects over time (Michaelowa and Jotzo 2005). With the right price signals, both industry and consumers generally benefit from more cost-effective emissions reductions, which might include purchasing or financing offsets (Wara 2007).

The Kyoto Protocol was instrumental in establishing the necessary foundation for carbon markets to develop. Adopted in 1997 at the Third Conference of the Parties of the United Nations Framework Convention on Climate Change, the Kyoto Protocol requires that Annex I nations reduce their greenhouse-gas emissions to 5\% below their total 1990 levels over the 2008-to-2012 commitment period. Annex I nations include industrialized countries that were in the Organization for Economic Cooperation and Development (OECD) in 1992, such as the United States, the United Kingdom and countries in the European Community. They also include countries with economies in transition (EIT parties) such as the Russian Federation, the Baltic States, and several Central and Eastern European states. Certain developed nations (OECD members but not EIT parties) contribute to an adaptation fund to be used in nonAnnex I (developing) nations such as China, India and Mexico. The purpose of the adaptation fund is to provide financial assistance to developing countries that are particularly susceptible to the effects of climate change, helping them to address adverse impacts.

The protocol includes provisions for trading emissions credits as a mechanism to reduce greenhouse-gas abatement costs, though member states can meet their targets with any combination of direct regulation, incentives, taxes or cap-and-trade. By Oct. 23, 2007, 175 countries had ratified the Kyoto Protocol (UNFCCC 2007), providing much of the world with a formal mechanism to regulate and trade emissions.

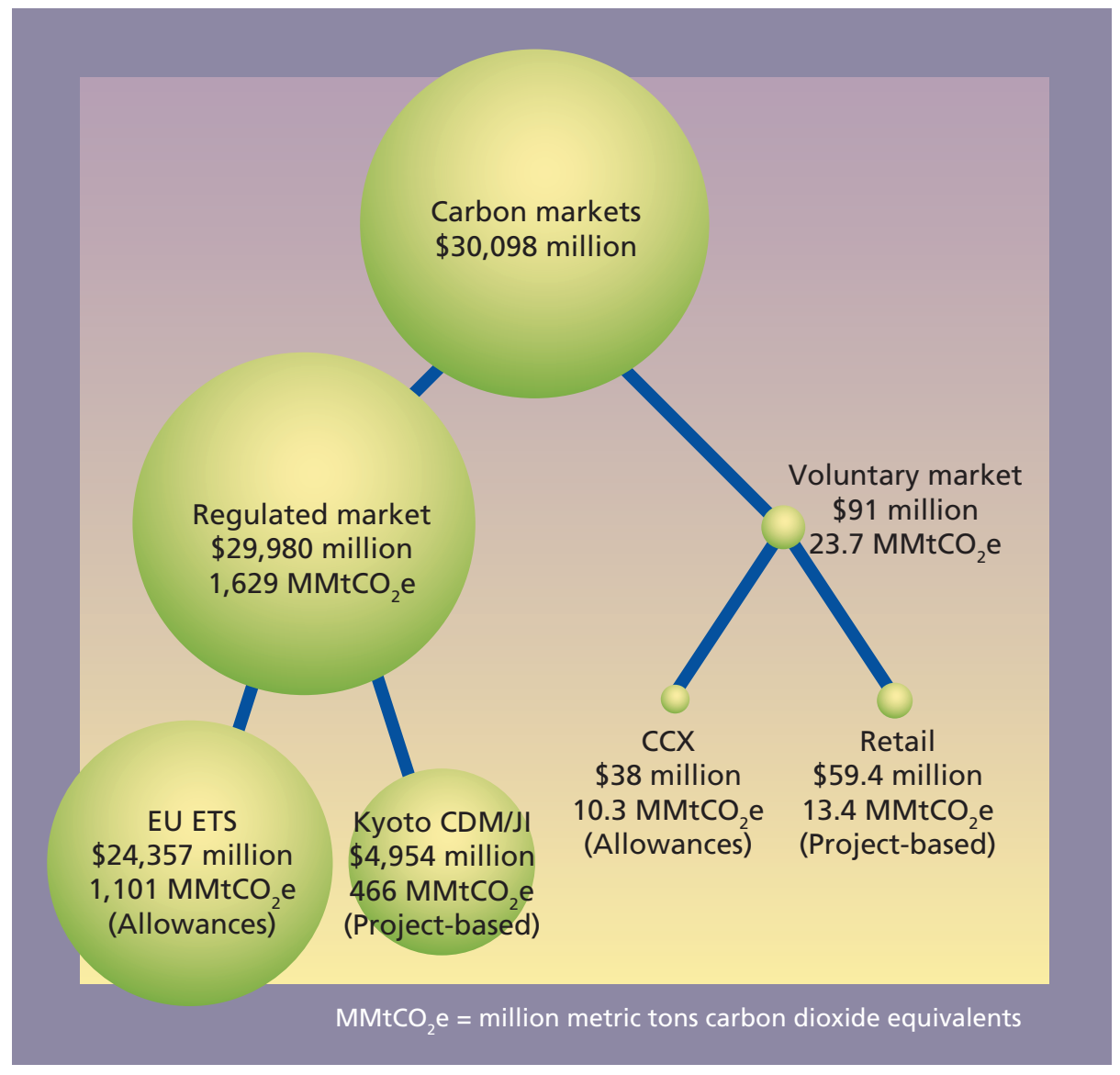

Fig. 1. Market trading, 2006. Total carbon market includes smaller market trades not shown; regulated market includes New South Wales and the U.K. Emissions Trading Schemes (ETS). Kyoto $\mathrm{CDM} / \mathrm{JI}$ = clean development mechanism/joint implementation; $\mathrm{CCX}=$ Chicago Climate Exchange. Adapted from Capoor and Ambrosi 2007; Hamilton 2007.

In nations such as the United States that have not yet ratified the Kyoto Protocol, and so are not bound by it, greenhouse-gas emissions regulations and trading mechanisms are also being established at subnational scales. These include upcoming limits in California and the Northeastern states. In the meantime, unregulated parties, from industries in nonratifying nations and non-Annex I nations to individual consumers worldwide, still look to a growing voluntary trading market to mitigate climate change.

\section{Regulated carbon markets}

Under the Kyoto Protocol, Annex I member states can meet their assigned targets in three ways:

Emissions trading. First, when greenhouse-gas allowances are exchanged by emissions trading, an Annex I party that is under its assigned target may transfer those excess credits (or assigned amount units) to another Annex I party that does not expect to meet its assigned target.

Joint implementation. Second, the Kyoto Protocol also allows carbon credits from project-based offsets. Article 33 (UNFCCC 1998) allows project-based credits for avoided deforestation, reforestation and afforestation, which entails planting forests in places that have not been forested for at least 50 years, to increase carbon stored in or decrease carbon released by soils and trees. Under Article 3.4, forest, crop and grazing land management can be used to generate carbon offsets (UNFCCC 2002). Joint implementation allows an Annex I party to develop and implement an emissions reduction (or sink) project in another Annex I party's territory and receive credit (emission reduction units [ERUs]) toward its own target. Most joint implementations to date have targeted economies in transition, but recently a New Zealand wind farm was implemented jointly. 
TABLE 1. Early greenhouse-gas offset projects

\begin{tabular}{llllc}
\hline Start date & Sponsors & Location & Type & Original mitigation estimate \\
\hline 1989 & Applied Energy Services, CARE & Guatemala & Forestry, agroforestry & MMtCO \\
1990 & U.S. Forest Service & United States & Tree planting (private land) & 60 \\
1991 & World Bank, Global Environmental Facility (GEF) & Philippines & Geothermal energy & $59-238$ \\
1991 & UN Development Program, GEF & Zimbabwe & Photovoltaic energy & * \\
1992 & Face Foundation, Innoprise Corp. & Malaysia & $\begin{array}{l}\text { Enrichment planting, forest rehabilitation, } \\
\text { sustainable timber }\end{array}$ & - \\
* Data unavailable. & & & 15.6
\end{tabular}

\section{Clean development mechanism.}

Third, under the clean development mechanism, Annex I parties can implement emissions reductions or sequestration projects in non-Annex I territories and receive certified emissions reductions that count toward their assigned target. These projects include hydropower, biomass generation, and methane and waste-heat recovery projects.

EU Emissions Trading Scheme. The largest carbon-trading volume to date has occurred under the EU Emissions Trading Scheme, a regulated, Kyotobased market mechanism. Each member state sets the maximum allowances (or greenhouse-gas caps) for five primary industrial sectors: power and heat, metals, cement, oil and gas, and pulp and paper. Regulated emitters (or installations) can buy and sell EU emissions allowances in order to meet targets set by their member state's plan (Europa 2007). Evolving since 2005, trades of emissions reduction units (offsets from joint implementation projects) and certified emissions reductions (offsets from clean development mechanism projects) are permitted under the scheme (European Parliament 2008), except for projects involving land use, land change and forestry. In principle, entities that purchase or invest in projects resulting in certified emissions reductions and emission reduction units convert the credits into allowances that satisfy the caps. The European Union limits the proportion of allowances that can be exchanged for project-based emissions reductions.

\section{The voluntary carbon market}

The voluntary market is fueled in part by the growing willingness of individuals and companies to make a commitment to offset their greenhouse-gas emissions.
Chicago Climate Exchange. In the United States, the voluntary market has grown beyond just offsets to include voluntary allowance trading. For example, the Chicago Climate Exchange is a cap-and-trade system with more than 300 members who have agreed to reduce their emissions $6 \%$ below their own individual baselines by 2010. Members must either directly reduce emissions or purchase offsets or credits to meet their targets. This exchange trades greenhouse gases in carbon financial instruments (CFI), each of which is equal to 0.0001 $\mathrm{MMtCO}_{2} \mathrm{e}$. Although project-based offsets are traded on the Chicago Climate Exchange, the majority of trading is allowance based.

In 2006, approximately 23.7 $\mathrm{MMtCO}_{2} \mathrm{e}$ were transacted in the voluntary market (fig. 1), of which 43\% was traded through the Chicago Climate Exchange (Hamilton et al. 2007). The remaining offset volume was traded through retail transactions such as TerraPass and similar companies. While the voluntary market still remains a relatively small proportion of overall trading, its volume grew considerably between 2005 and 2006; the Chicago Climate Exchange was up by more than $900 \%$ and retail transactions doubled (Capoor and Ambrosi 2007).

Forestry projects. Several voluntary greenhouse-gas offset projects were initiated in the early 1990s by public, private and nonprofit entities. These were mostly forestry-based projects in developing nations to support conservation programs (table 1). One of the first was initiated in 1989 by Applied Energy Services and the humanitarian organization CARE International, in conjunction with the World Resources Institute (Trexler et al. 1989). At the time, CARE was seeking funds to extend and expand its work in Guatemala. The project involved offsetting emissions from a new Applied Energy Services coal-fired power plant in Connecticut with a range of activities in Guatemala, including agroforestry and multiuse plantings for community woodlots, fuel wood, soil conservation, fruit and nut production, alley cropping and live fencing. The World Resources Institute estimated that approximately $60 \mathrm{MMtCO}_{2}$ would be sequestered over 40 years (Trexler et al. 1989), though that estimate has since been revised to $37 \mathrm{MMtCO}_{2} \mathrm{e}$ (WRI 2007).

In 1990, the Dutch Electricity Generating Board set up the Face Foundation to mitigate greenhouse-gas emissions through forestry (www. stichtingface.nl). In 1992, the Face Foundation and the Innoprise Corporation jointly initiated the first Face project in Sabeh, Malaysia (Stuart and Moura 1998), which included enrichment planting and restoration for managed timber harvesting. The expectation was that the offset project would sequester 15.6 $\mathrm{MMtCO}_{2} \mathrm{e}$ over its 99-year lifetime.

One of the first U.S. government programs that publicized the benefits of climate-change mitigation was also a forestry project. In 1990, the U.S.

Forest Service's America the Beautiful Program planted trees on private land, with predicted offsets of 59 to 238 $\mathrm{MMtCO}_{2}$ e per year after 10 years of planting (Kinsman and Trexler 1993).

Renewable energy projects. Around the same time, several energy-based projects were surfacing. In 1991, the U.N. Development Program, U.N. Environment Program and World Bank helped to establish the nowindependent Global Environment Facility (http://gefonline.org) to provide funding for developing countries to protect global environmental resources (Kinsman and Trexler 
1993). In its first year, the Global Environment Facility approved six projects aimed at climate-change research and mitigation. Two focused on implementing energy-saving technologies, including a geothermal electric power generation project in the Philippines and a photovoltaic project in Zimbabwe.

These early prototypes served as a proving ground, testing the feasibility of offset projects and helping to refine methodologies. Since the early 1990s, both the number and range of offset projects have grown. Although the voluntary and regulated offset markets cover a more or less similar range of sectors, forestry and renewable energy projects currently dominate the voluntary market. This is in contrast to Kyoto's clean development mechanism and joint implementation projects, where the majority of offset projects are aimed at decreasing emissions of industrial gases (fig. 2).

\section{Offset supply pathways}

A number of offset supply pathways have developed, due to the rapidity with which carbon demand has increased as well as the lack of formal government oversight or regulatory policy structure for managing supply in the voluntary offset market (fig. 3). Credits can pass directly from developer to buyer, or indirectly through a verifier, which may or may not be certified by a regulatory agency, an aggregator/wholesaler and/ or a retailer. Project developers tend to organize a range of different-sized offset projects (Hamilton et al. 2007). They sell offsets to aggregators or wholesalers, retailers and even directly to consumers. The aggregators bundle smaller offsets for bulk sales, while retailers pass along smaller numbers of credits to individuals and organizations. Both retailers and wholesalers own portfolios of credits.

The voluntary supply chains are becoming increasingly diversified, with fewer big players and greater product specialization. This contrasts with the pathways for allowances, which are tradable within the EU Emissions Trading Scheme and on the Chicago Climate Exchange. Allowances pass through EU member states (and regulated sectors)

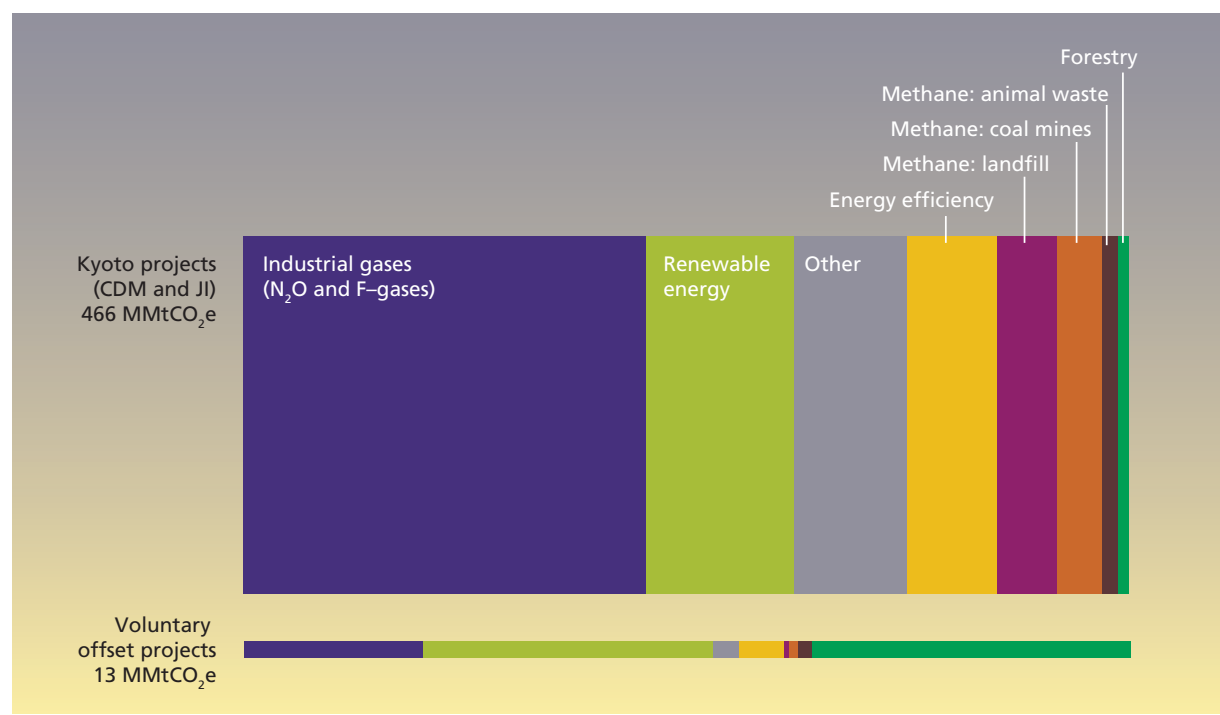

Fig. 2. Project type and proportional volume, 2006. Adapted from Bellassen and Leguet 2007. to the market, while carbon financial instruments pass through the Chicago Climate Exchange.

In 2006, about half to three-quarters of the demand for carbon credits was estimated to come from businesses offsetting emissions (Hamilton et al. 2007). Individuals who either purchase offsets through retailers or buy products from companies that offset their emissions drive about a third of market demand; the latter can be thought of as carbon "rebates." Finally, while still a small proportion of the total demand, an increasing number of event organizers and nonprofit and governmental organizations are offsetting their carbon emissions.

While still fairly small, the retail offsets market could play an important role

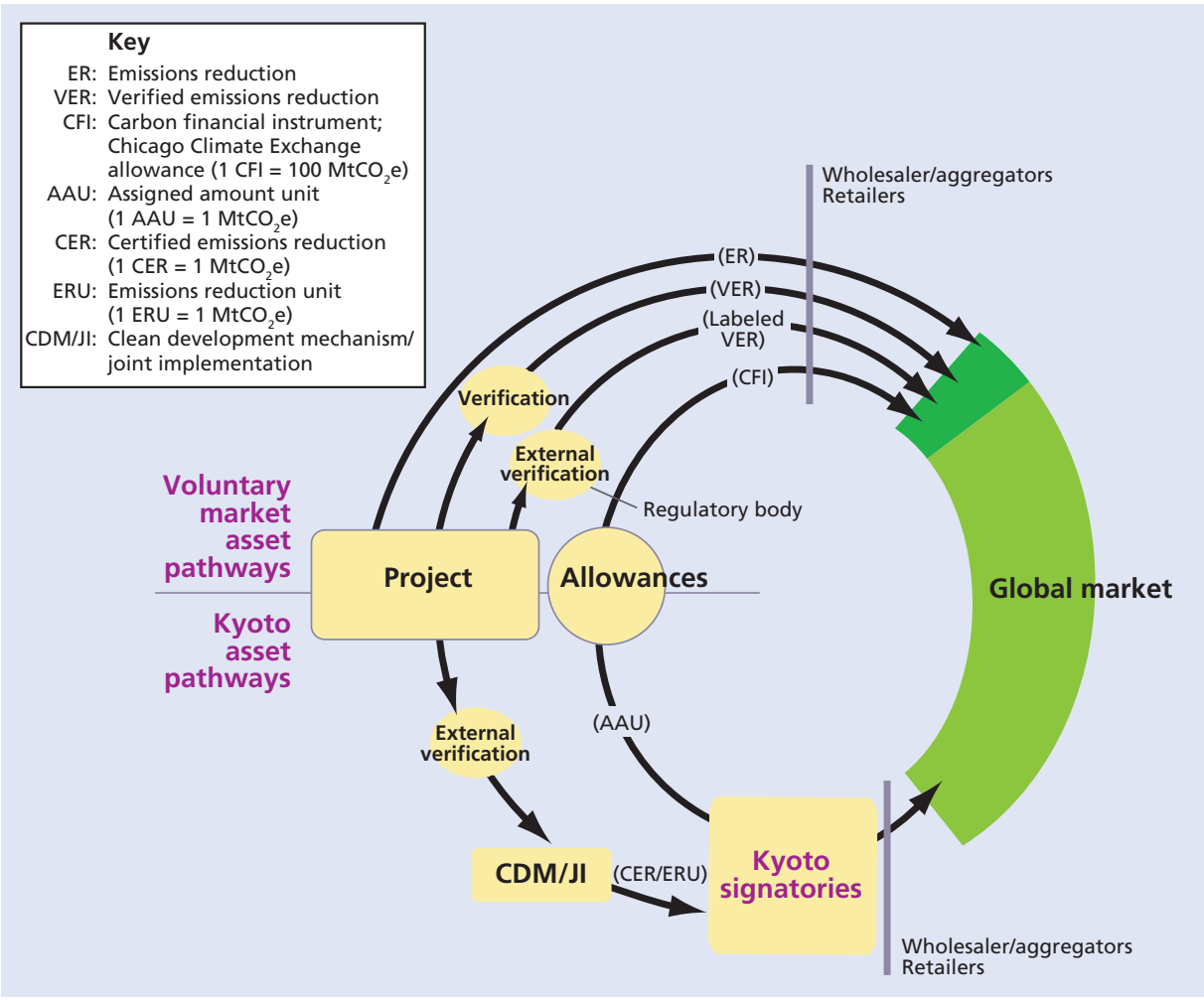

Fig. 3. Conceptual pathways to the carbon market. 


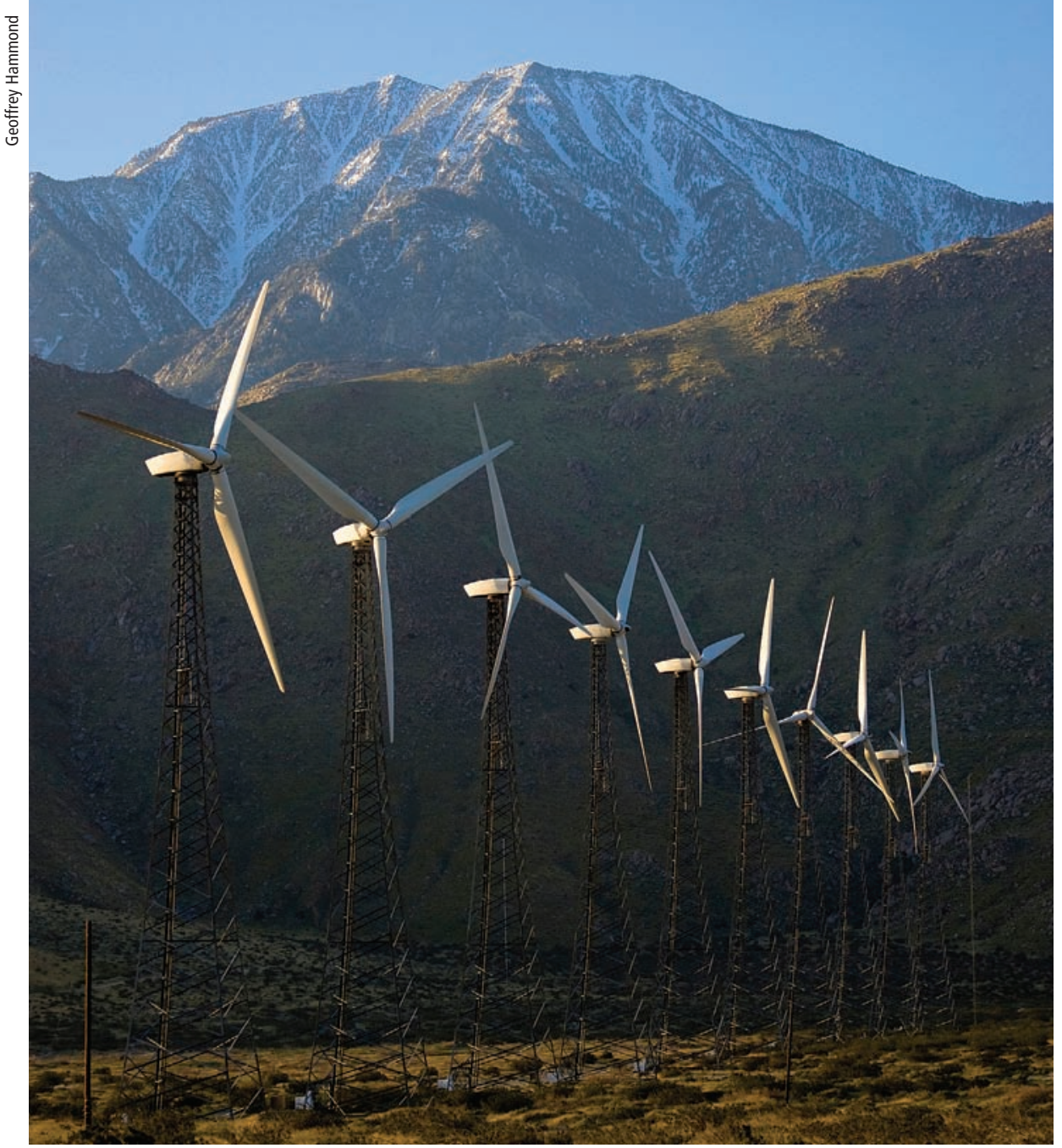

Carbon markets, both regulated and voluntary, set caps for greenhouse-gas emissions. When polluters exceed these targets, they can pay to mitigate or offset the environmental damage. For example, investments in cleaner wind power can offset more heavily polluting sources. Above, a Palm Springs wind farm.

in consumer perceptions of carbon trading (Capoor and Ambrosi 2007). Retail offset credits are referred to as carbon offsets or "verified" when they have been verified by an independent third party, or as verified emissions reductions (VER) when the verifier has been certified by a regulatory body.

Rather than being driven by a cap, the voluntary market is driven by individual and corporate buyers, who are motivated by philanthropy, internal goals and sustainability reporting, corporate responsibility, public relations and branding, reduced liability, cost avoidance, regulation preemption, and appeal to consumers and investors (Hamilton et al. 2007; Arora and Cason 1996; Hoffman 2005; Videras and Alberini 2000; Vidovic and Khanna 2007; Welch et al 2000). have clearly defined boundaries and a well-demonstrated baseline level of emissions, with monitoring methodologies to measure real emissions reductions. Reductions must be verifiable and "additional"; emissions reductions are counted as additional if they would not have occurred in the absence of the project. So-called additionality is often the most difficult requirement, especially for land-use change and forestry projects (Chomitz 2000). Offset projects must also account for "leakage," or changes in emissions outside of the project boundaries that may occur as a result of the project. Other criteria may include whether an emissions reduction is reversible, and if so, on what time scale, and whether project-related social and environmental effects on a community can be appropriately mitigated (Capoor and Ambrosi 2007; Chomitz 2000). There is also some concern that over time, a continued lack of confidence in voluntary offset quality could extend to other projects in the categories of clean development mechanism and joint implementation.

Standards. Partially as a result of this concern, new protocols are proposed almost monthly for offset standards or certification programs. Among the better known standards are ISO 14064 (a voluntary carbon standard), the Gold Standard (endorsed by a large number of nonprofit organizations), the Voluntary Carbon Offset Standard and the Voluntary Carbon Standard. In addition, the U.K. Department of Environment and Rural Affairs has prepared a Code of Best Practices to assist consumers in identifying quality offsets.

Registries. Greenhouse-gas registries are also a critical component for improving the quality of voluntary market transactions. Registries provide accounting and tracking systems for offsets, which can help to reduce the double-counting of carbon credits. For example, the Canadian Greenhouse Gas Challenge and the World Economic Forum serve as tracking systems, and the Environmental Resources Trust GHG Registry and the Bank of New York Global Registry provide carbon accounting systems. The California Climate Action Registry provides both a tracking system and some sector- 
specific protocols (accounting mechanisms), and is currently serving as the model for a national registry.

\section{Voluntary agricultural offsets}

In most countries, agriculture is one of the few industries that currently has the opportunity to benefit from the voluntary carbon market without the burden of direct costs due to regulation, although farms may suffer from the indirect costs of greenhouse-gas regulation (such as higher fuel or supply prices) and adaptation costs if regulation is unable to prevent climatechange impacts. So far, agriculture has not been subject to carbon caps in the EU Emissions Trading Scheme or in proposed U.S. cap-and-trade programs, largely because it is difficult to measure greenhouse-gas emissions from agricultural activities such as soil tillage, animal waste, land conversion and fuel use (European Commission 2008). However, the New Zealand government (2007) currently has plans to cap agricultural emissions.

Agricultural production entities that are not regulated may be able to sell carbon reductions as offsets, if an emitting farm is willing to assume the costs of monitoring and self-enforcement to reduce its emissions. As of May 2008, the Chicago Climate Exchange had approved 10 agricultural soil offset projects and 14 agricultural methane-reduction projects (four of which are in California), and had approved the methodology for rangeland soil carbon management (CCX 2007a, 2007b). Retail offsets have also included projects to capture methane and build wind energy infrastructure on farms (NativeEnergy 2007).

\section{Emerging U.S. markets}

The regulation of greenhouse gases will undoubtedly affect many existing industries, from energy and transportation to agriculture and forestry. The effect on each market is a function of the structure and rules of regulatory mechanisms. Within the United States, climate change is being addressed through a number of different state, local and voluntary carbon-emissions reduction initiatives.

Regional agreements. At present, three regional agreements provide a framework for cap-and-trade schemes between states: the Regional Greenhouse Gas Initiative, the Western Climate Initiative and the Midwest Greenhouse Gas Reduction Accord. The Regional Greenhouse Gas Initiative encompasses emissions from power plants in 10 Northeast states, and began trading 2009 emissions credits in 2008. The Western Climate Initiative (2008) began in February 2007 and released a cap-and-trade program proposal in September 2008. This program would encompass seven Western states including California and four Canadian provinces beginning in 2012, and is designed to reduce emissions to $15 \%$ below 2005 levels by 2020. The Midwest Accord includes six states and one Canadian province, which agreed in November 2007 to establish a cap-andtrade program within 30 months.
With 23 U.S. states involved in regional agreements as of July 2008, and 10 states and the District of Columbia as official observers (www.rggi.org, www.midwesternaccord.org, www. westernclimateinitiative.org) the lack of federal guidance does not seem to have hampered mobilization to reduce greenhouse gases in the United States.

California mandate. The California Global Warming Solutions Act of 2006 (AB32) mandates reductions in the state's greenhouse-gas emissions to 1990 levels by 2020. This sets the stage for yet another entry into the regulated carbon-trading market. The Act authorizes - but does not require the California Air Resources Board to employ market-based regulatory mechanisms to achieve greenhouse-gas emissions reductions (CARB 2008a).

The board's scoping plan, adopted in December 2008, includes regulations, fees and voluntary measures, some of which would be partially nested within a cap-and-trade program that could potentially cover up to $85 \%$ of the state's emissions by 2020 (CARB 2008a). The specific measures are expected to achieve $140 \mathrm{MMtCO}_{2} \mathrm{e}$ in reductions by $2020,112 \mathrm{MMtCO}_{2} \mathrm{e}$ of which would be in capped sectors. An additional 34 $\mathrm{MMtCO}_{2}$ e would also be reduced under the cap-and-trade program, such that the total emissions of capped sectors would be fixed at $365 \mathrm{MMtCO}_{2} \mathrm{e}$ in 2020.

The plan also calls for linkages with Western Climate Initiative partner programs, although it stipulates that no more than $49 \%$ of required reductions can come from the combination of al-

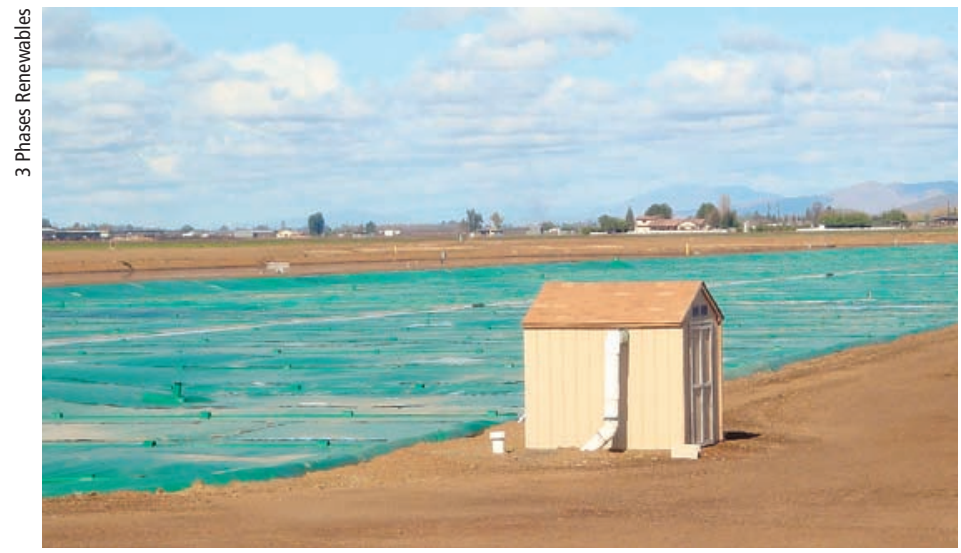

Hilarides Dairy in Lindsay, Calif., has installed covers on its manure lagoons to capture methane for electricity generation and vehicle fuel. The dairy hopes to capture the economic value of destroying methane by selling carbon offsets once the market is established.

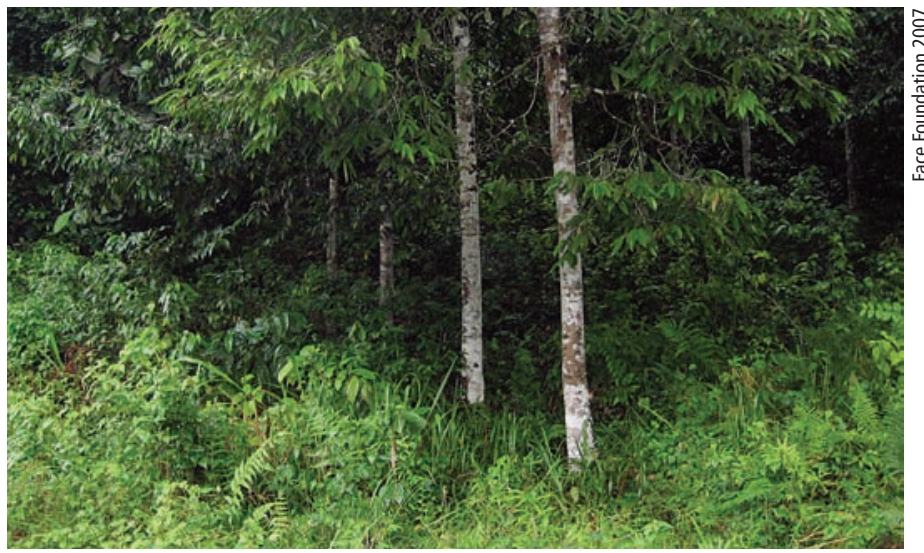

The Dutch Electricity Generating Board set up the Face Foundation in 1990 to mitigate energy-related emissions via forestry. Its first project, with Innoprise Corporation, was to restore a degraded forest in Sabeh, Malaysia. 


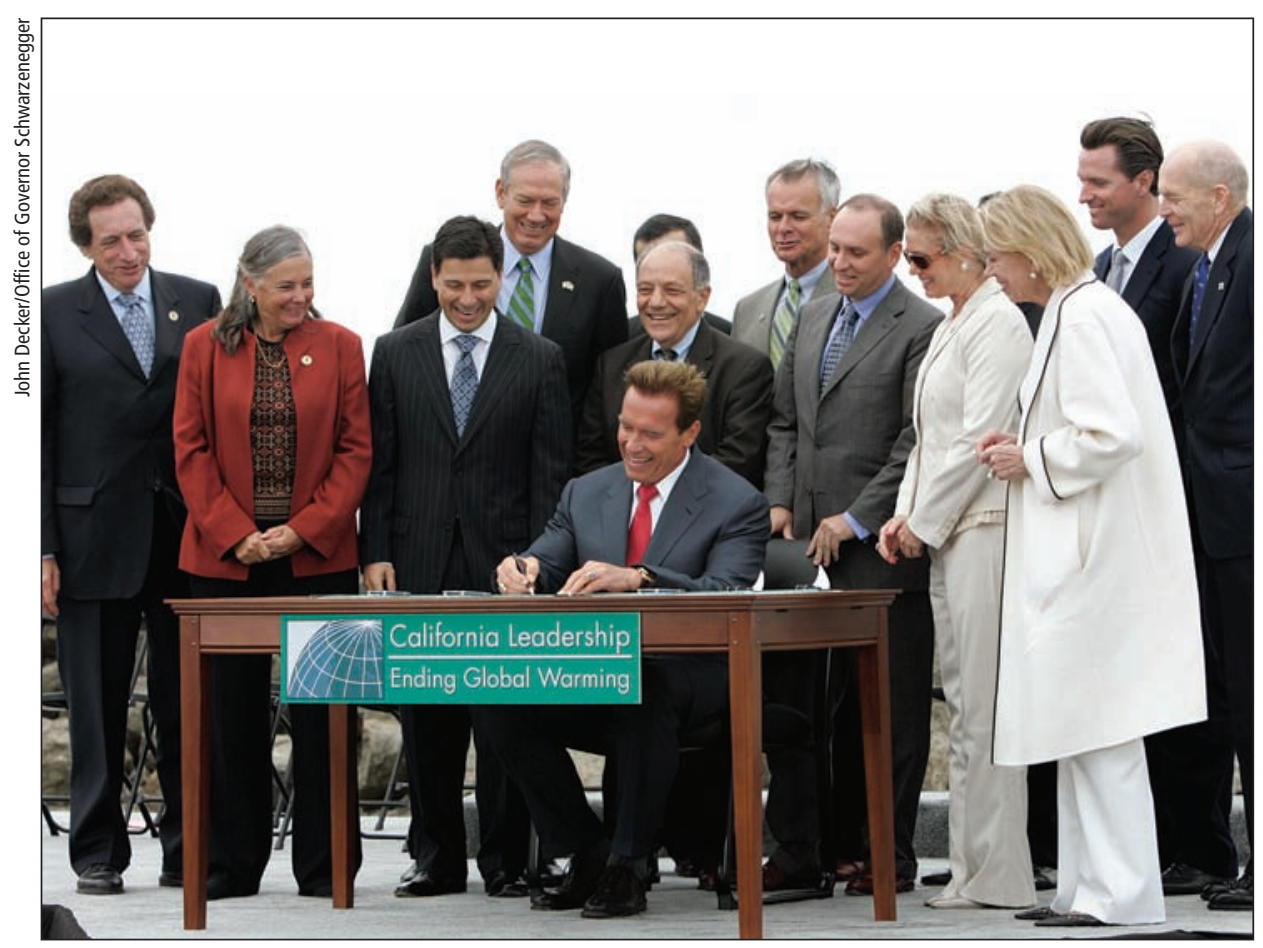

On Sept. 27, 2006, on Treasure Island in San Francisco, Gov. Arnold Schwarzenegger signed $A B 32$, landmark legislation to address climate change by reducing California's greenhousegas emissions to 1990 levels by 2020. Among its provisions, AB32 authorizes the California Air Resources Board to institute market-based emissions trading.

lowances outside California and of the total offsets. Verification and offset approval are emphasized.

Western Climate Initiative. The Western Climate Initiative (2008) plans to integrate its cap-and-trade program with California's trading program. The first compliance period begins in 2012 and will include emissions from electricity generation, industrial processes, and combustion at industrial and commercial facilities. The second compliance period begins in 2015, when the program will expand to include fuel combustion at smaller sources and the combustion of transportation fuels.

\section{California's ag carbon market}

Although agricultural emissions are not included in California's proposed cap-and-trade program or mandatory measures, they are under consideration for voluntary reductions and potential future measures (CARB 2008b). California agriculture will also be indirectly affected by several greenhousegas-reduction policies.

California Air Resources Board. In September 2008, the California Air Resources Board adopted a methodol- ogy to calculate emissions from manure digesters (CARB 2008b). Voluntary investments in manure digesters will be encouraged with, for example, marketable offset credits, renewable energy incentives and/or utility contract incentives. The possibility of making manure digesters mandatory for large dairies will be evaluated in the plan's 5-year update. The plan also indicates that the state will consider developing protocols to quantify greenhouse-gas reductions from carbon sequestration in rangelands and woodlands, although it does not yet indicate whether those protocols would be used for voluntary or tradable offsets.

Western Climate Initiative. Under the Western Climate Initiative, the development of protocols to approve offsets from agricultural soil sequestration and manure management is a priority. Approving these offsets would likely increase and eventually stabilize the agricultural offset market. Given proposed linkages between the Western Climate Initiative and the California Air Resources Board, the former's offset rules may apply in the latter's cap-andtrade program. Although the Western Climate Initiative allows states some

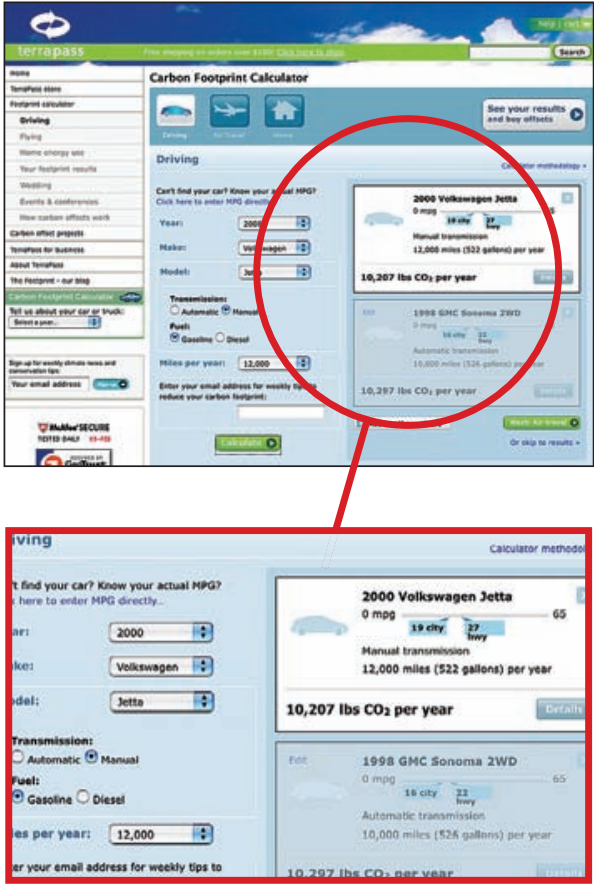

TerraPass is one of several organizations that allows consumers to calculate specific dollar amounts to offset their energy usage when at home, driving or flying, or for events such as weddings or conferences.

flexibility, California would likely follow suit with tradable agriculture offsets, given its development of methods for calculating emissions reductions from manure digesters and its investigation of carbon-sequestration protocols.

Fertilizer, energy use and biomass. Emissions from fertilizer are not included in California's proposed program, but the California Air Resources Board is conducting research into nitrogen fertilizer emissions to improve baseline calculations and management practices. Additionally, the board is currently working to enforce regulations that apply to the sale of used diesel agricultural engines and to increase fleet turnover of off-road agricultural equipment. The board's scoping plan also indicates that it will consider increasing the fuel efficiency of farm equipment, using water more efficiently (which reduces greenhousegas emissions by reducing the energy needed to convey water) and using biomass to produce energy. The Western Climate Initiative plan explicitly considers the combustion of approved biomass and biofuels to be carbon neutral. These policies will put biofuels and 
energy produced from biomass - and the crops used to make them - at an advantage in the regulated markets of the future.

\section{California's influence}

Although California will learn from other trading schemes, carbon markets are still in relative infancy and their designs are being refined. While federal rules may eventually preempt regional and state efforts, California's early market designs may "serve as a model for the federal program" (CARB 2008a).

California's environmental justice community has expressed concerns about the distribution of the economic and public health effects of climate policy, and AB32 requires that reduction measures avoid disproportionate impacts on vulnerable communities. Given the California Air Resources Board's emphasis on linkages with other trading systems and the legislative requirement to develop equitable market mechanisms, if the board succeeds in reconciling the concerns of low-income and minority communities with a stable and efficient cap-and-trade system, the rules designed in California may have an important influence on the design of larger national and global cap-and-trade schemes.

Capoor and Ambrosi (2007) note that a market-based approach is only as good as the target set by policymakers and the integrity with which the market is viewed. The current carbon market is still evolving. In November 2007, the long-awaited International Transaction Log opened, and Japan became the first nation with a transparent registry system. Likewise, the Kyoto Protocol entered its commitment period in 2008, and the strengths and limitations of market-based approaches will be tested. Where markets fail, mitigation may be needed to address any unintentional inequity and environmental impacts that result from greenhouse-gas market pressures and from climate change itself.

As the California carbon marketplace begins to form and take hold, the extent to which each sector participates and the impacts on various communi-

\section{References}

Arora S, Cason T. 1996. Why do firms volunteer to exceed environmental regulations? Understanding participation in EPA's 33/50 Program. Land Econ 72(4):413-32

Bellassen V, Leguet B. 2007. The emergence of voluntary carbon offsetting. Mission Climate, Res Rep No 11. Caisse des Depots, Paris, France.

[CARB] California Air Resources Board. 2008a. Climate Change Proposed Scoping Plan: A framework for change. www.arb.ca.gov/cc/scopingplan/document/ psp.pdf. p 34.

CARB. 2008b. Manure Management Protocols. www. arb.ca.gov/ag/manuremgmt/protocols/protocols.htm.

Capoor K, Ambrosi P. 2007. States and Trends of the Carbon Market 2007. World Bank. Washington, DC. $45 \mathrm{p}$.

[CCX] Chicago Climate Exchange. 2007a. CCX Registry Offsets Report. www.chicagoclimatex.com/offsets/ projectReport.jsf (accessed 5/08).

CCX. 2007b. Rangeland Soil Carbon Management Offsets. www.chicagoclimatex.com/content. jsf?id=1101 (accessed 5/08)

Chomitz K. 2000. Evaluating carbon offset projects from forestry and energy projects: How do they compare? World Bank Policy Research Working Paper 2357. World Bank Infrastructure and Environment, Development Research Group. Washington, DC

Europa. 2007. SCADPlus: Greenhouse Gas Emission Allowance Trading Scheme, Activities of the European Union: Summaries of Legislation. European Union Online. http://europa.eu.

European Commission. 2008. Climate change: The challenges for agriculture. European Commission Directorate-General Agriculture and Rural Development. http://ec.europa.eu/agriculture/publi/fact/ climate_change/2008_en.pdf.

European Parliament (ed.). 2004. Directive 2004/101/ EC of the European Parliament and of the Council of 27, October 2004 amending Directive 2003/87/EC establishing a scheme for greenhouse-gas emission allowance trading within the Community, in respect of the Kyoto Protocol's project mechanisms.

Fahrenthold D, Mufson S. 2007. Cost of saving the climate meets real-world hurdles. Washington Post, Aug. 16, p A01.

Hamilton K, Bayon R, Turner G, Higgins D. 2007. State of the Voluntary Carbon Market. Ecosystem Marketplace. Washington, DC. $59 \mathrm{p}$.

Hoffman A. 2005. The business logic behind voluntary greenhouse gas reductions. Cal Manage Rev 47(3):21-46.
Kinsman J, Trexler M. 1993. Terrestrial carbon management and electric utilities, water. Air Soil Pollut 70:545-60.

Michaelowa A, Jotzo F. 2005. Transaction costs, institutional rigidities and the size of the clean development mechanism. Energy Pol 33(4):511-23.

NativeEnergy. 2007. Our Projects. www.nativeenergy. com/projects.html.

New Zealand government. 2007. A guide to the climate change (emissions trading and renewable preference) bill. Factsheet 13. Ministry for the Environment. Wellington, NZ.

Stuart M, Moura C. 1998. Climate change mitigation by forestry: A review of international initiatives. In: Mayers J (ed.). Policy That Works for Forests and People. Series No. 8. International Institute for Environment and Development. London, UK. 68 p.

Trexler M, Faeth P, Kramer J. 1989. Forestry as a response to global warming: An analysis of the Guatemala agroforestry and carbon sequestration project. World Resources Institute. Washington, DC.

[UNFCCC] United Nations Framework Convention on Climate Change. 1998. The Kyoto Protocol to UNFCCC. Doc FCCC/CP/1997/7/Add.1. United Nations, New York.

UNFCCC. 2002. Report of the Conference of the Parties on its Seventh Session. Doc FCCC/CP/2001/13/ Add.1. United Nations, Marrakesh.

UNFCCC. 2007. Kyoto Protocol. http://unfccc.int/ kyoto_protocol/items/2830.php (accessed 11/16/07).

Videras J, Alberini A. 2000. The appeal of voluntary environmental programs: Which firms participate and why? Contemp Econ Pol 18(4):449-61

Vidovic M, Khanna N. 2007. Can voluntary pollution programs fulfill their promises? Further evidence from EPA's 33/50. J Env Econ Manage 53:180-95.

Wara M. 2007. Is the global carbon market working? Nature 445(7128):595-6.

Welch E, Mazur A, Bretschneider S. 2000. Voluntary behavior by electric utilities: Levels of adoption and contribution of the climate challenge program to the reduction of carbon dioxide. J Pol Anal Manage 19(3):407-25.

Western Climate Initiative. 2008. Recommendations for the WCI Regional Cap-and-Trade Program. www. westernclimateinitiative.org.

[WRI] World Resources Institute. 2007. CARE Guatemala Agroforestry Project. www.wri.org/climate/ sequestration_description.cfm?CarbonSeqID =10 (accessed 10/19/07). ties will be a function of the structure and rules associated with final regulatory mechanisms. However, public confidence will depend mostly on perceptions of offset quality, the transparency of accounting, and the distribution of costs and benefits of climate policy.
D. Niemeier is Professor, Civil and Environmental Engineering, and Director, John Muir Institute on the Environment, and D. Rowan is Ph.D. student in Ecology and M.S. student, Department of Agricultural and Resource Economics, UC Davis. 